Enferm Bras 2019;18(5):610-1

https://doi.org/10.33233/eb.v18i5.3362

\title{
EDITORIAL \\ Gravidez na adolescência: um desafio intersetorial
}

Alessandra Lima Vicentim, M.Sc. ${ }^{\star}$, Natália Sperli Geraldes Marin dos Santos Sasaki ${ }^{\star \star}$, Maria de Lourdes Sperli Geraldes Santos, D.Sc. ${ }^{\star \star *}$

*Enfermeira obstetra, Mestre em Enfermagem pelo Programa de Pós-Graduação em Enfermagem da Faculdade de Medicina de São José do Rio Preto (FAMERP), servidora pública da Secretaria de Saúde de São José do Rio Preto/SP, docente do curso de Enfermagem da União das Faculdades dos Grandes Lagos (Unilago), ${ }^{* *}$ Enfermeira obstetra docente $e$ coordenadora do curso de enfermagem da União das Faculdades dos Grandes Lagos - Unilago, docente do Programa de Mestrado em Enfermagem da FAMERP, ${ }^{* \star *}$ Enfermeira, doutora pelo Programa Interunidades de Doutoramento em Enfermagem pela Escola de Enfermagem de Ribeirão Preto (USP), professora adjunta IV da Faculdade de Medicina de São José do Rio Preto/SP (FAMERP) e docente da graduação e pós-graduação em Enfermagem da FAMERP

Alessandra Lima Vicentim: alessandravicentim@gmail.com

Natália Sperli Geraldes Marin dos Santos Sasaki: nsperli@gmail.com

Maria de Lourdes Sperli Geraldes Santos: mlsperli@gmail.com

A adolescência é uma fase de transição entre a infância e a vida adulta, permeada por transformações físicas, biológicas, sociais e emocionais, representando um marco para a maioria dos indivíduos. Cronologicamente, a Organização Mundial da Saúde (OMS) define adolescência como o período compreendido entre os 10 e 19 anos de idade, tal definição também é adotada pelo Ministério da Saúde no Brasil [1-2] e programas e ações de saúde voltados à adolescência devem levar em consideração esta faixa etária.

Nesta fase ocorre a puberdade e o início dos relacionamentos amorosos e, consequentemente, a primeira relação sexual. Atualmente a coitarca das adolescentes tem ocorrido em média aos 14 anos, porém percebe-se tendência de que a mesma ocorra de forma cada vez mais precoce. Frente ao início das relações sexuais e com a adolescente fisiologicamente pronta para a reprodução, a gravidez torna-se um fato, caso não sejam tomadas medidas para sua prevenção. Há de se considerar que mesmo pronta fisicamente, geralmente não acontece nos âmbitos social e emocional para exercer a parentalidade. Assim, a gestação na adolescência traz complicações consideráveis para esta população tanto no presente quanto no futuro.

Tem-se observado a ocorrência da gravidez na adolescência em um perfil específico, adolescentes casadas ou em união estável, que não exercem atividade remunerada e que interromperam os estudos. Estas adolescentes podem ver no papel de mãe um meio para aquisição de "status" social e uma forma de reconhecimento. Tal fato pode ser compreendido quando esta não possui outros projetos ou expectativas ligadas ao crescimento pessoal e/ou profissional ou incentivo para os mesmos, sendo influenciada pela situação socioeconômica.

Um fato considerável atualmente é que estas meninas possuem conhecimento em relação aos métodos contraceptivos, principalmente do preservativo masculino $\mathrm{e}$ anticoncepcional hormonal oral, porém somente o conhecimento não se traduz em uso, e para que ele ocorra faz-se necessário assegurar o acesso aos métodos e o combate às barreiras que prejudicam a sua utilização.

Frente a este painel, há três pilares essenciais para a prevenção da gravidez na adolescência: a escola, a família e a atenção básica. Para o sucesso das ações é necessário que o trabalho ocorra de forma intersetorial. A escola é um local privilegiado para a execução de ações de educação em saúde, pois é um espaço para aquisição de conhecimento, socialização e debates, porém vê-se a necessidade de discutir a saúde sexual e reprodutiva de forma cada vez mais precoce, pois se abordado somente no ensino médio, oitavo ou nono ano, talvez as ações preventivas não atinjam o esperado, visto o início cada vez mais cedo das relações sexuais. Quanto à família, sabe-se que a supervisão dos pais ou responsáveis retarda o início da relação sexual e aumenta as taxas de uso de métodos contraceptivos. Por fim, a atenção 
básica, e dentro dela o enfermeiro, tem trabalhado a saúde sexual e reprodutiva e a prevenção da gravidez na adolescência através da educação em saúde e ações em conjunto com escolas e comunidade, consultas de enfermagem, grupos de adolescentes e planejamento familiar.

Vale a pena ressaltar que o acesso do adolescente à unidade de saúde deve ser facilitado e o mesmo deve ser visto como indivíduo que necessita de atenção integral, privacidade e confidencialidade pelos profissionais de saúde, além de acolhido de forma adequada. A Estratégia de Saúde da Família e o Programa Saúde na Escola são instrumentos essenciais para aproximação desta população, criação de vínculo e queda de barreiras, trazendo o adolescente para dentro da unidade de saúde. Entretanto, apesar dos esforços, muitas vezes as ações realizadas parecem insuficientes para a prevenção da gravidez na adolescência. Talvez realmente sejam, pois além de discutir saúde sexual e reprodutiva, um tema essencial deve ser trabalhado, o empoderamento das adolescentes, capacitando-as para a tomada de decisões, para a realização de projetos e planos, para a continuidade dos estudos, profissionalização e entrada no mercado de trabalho, para que estas sejam capazes de atingir o crescimento pessoal e/ou profissional e superar as vulnerabilidades a que está sujeita em seu meio através do incentivo e de oportunidades. Portanto, trabalhar o empoderamento também é prevenir a gravidez na adolescência.

\section{Referências}

1. World Health Organization [homepage na Intenet]. Geneva: WHO; 2018 [citado 2018 Nov 14. Adolescent health; [aproximadamente 3 telas]. Disponível em: http://www.who.int/maternal child adolescent/adolescence/en/

2. Brasil. Ministério da Saúde. Proteger e cuidar da saúde de adolescentes na atenção básica. Brasília: Ministério da Saúde; 2017. 